\title{
MESOPOROUS HKUST-1 SYNTHESIZED USING SOLVOTHERMAL METHOD
}

\author{
R. Ediati", S.K. Dewi, M.R. Hasan, M. Kahardina, I.K. Murwani \\ and M. Nadjib
}

Department of Chemistry, Institut Teknologi Sepuluh Nopember, Surabaya 60111, Indonesia

*E-mail : rediati@chem.its.ac.id

\begin{abstract}
Metal-organic frameworks type HKUST-1 were synthesized using a solvothermal method with reactants of copper(II) nitrate trihydrate and benzene-1,3,5-tricarboxylic acid in a solvent mixture of ethanol, DMF and water with a volume ratio of 1:1:1. The synthesis of HKUST-1 was carried out by adding cetyltrimethylammonium bromide (CTAB) surfactant and acetic acid as a modulator. The process of synthesis was done in a vial bottle at a temperature of $100{ }^{\circ} \mathrm{C}$ for $10 \mathrm{~h}$. The obtained solids, in the form of a light blue colored powder, were characterized by X-Ray Powder Diffraction (XRD), Fourier Transform Infrared Spectroscopy (FTIR), Scanning Electron Microscopy (SEM), and nitrogen adsorption-desorption methods. The diffraction patterns of the obtained solids show the characteristic peaks of the HKUST-1 at $2 \theta$ of $6.7,9.5,11.5$ and $13.4^{\circ}$, respectively. The surface morphology of the synthesized HKUST-1 was octahedral forms with a particle size of between 16.4-17.9 $\mu \mathrm{m}$. The HKUST-1 obtained with the addition of CTAB surfactant had a nitrogen adsorption-desorption isotherm of type IV, characteristic to a mesoporous material, with a specific surface area as high as $1010 \mathrm{~m}^{2} / \mathrm{g}$ and pore diameter of 9.2 nm.
\end{abstract}

Keywords: Mesoporous, HKUST-1, Solvothermal, Surfactant, Acetic Acid Modulator

(C) RASĀYAN. All rights reserved

\section{INTRODUCTION}

Metal-organic framework (MOF) is a crystalline porous material composed of co-ordinated bonds between metal ions and organic ligands ${ }^{1}$. Besides having advantages, which are such as good thermal stability, a wide variety of structure and large surface area ${ }^{2}$, MOF also has disadvantages. It has been reported that some of MOF materials are classified as microporous materials with a pore diameter of less than $2 \mathrm{~nm}$, in which this will restrict the molecule diffusion and the mass transfer to the active sites of the MOF, and hence will have an impact towards its applications ${ }^{3,4}$.

One type of MOF that has been getting a lot of attention is the Cu-BTC or better known as HKUST-1 (Hong Kong University of Science and Technology-1). HKUST-1, composed of copper which coordinated to benzene-1,3,5-tricarboxylic (BTC) ligand, was first synthesized by Chui and co-workers in 1999. In the HKUST-1 frameworks, the $\mathrm{Cu}^{2+}$ ion formed a dimer structure, where each $\mathrm{Cu}^{2+}$ ions coordinated with the four oxygen from the BTC linker and $\mathrm{H}_{2} \mathrm{O}$ molecules ${ }^{5}$. HKUST-1 has a face-centered cube crystal structure with a pore diameter of $0.5 \mathrm{~nm}$ to $0.9 \mathrm{~nm}^{6}$. HKUST-1 has a variety of advantages, amongst them is that it has a large pore volume and surface area, along with its high thermal stability which can reach a temperature of around $280{ }^{\circ} \mathrm{C}$, hence making HKUST-1 a very potential material to be applied in the fields of adsorption, gas storage and used as a catalyst ${ }^{7}$.

HKUST-1 is mostly synthesized with many different combinations or modifications to increase the quality of the materials. In 2011, Feldblyum and co-workers synthesized HKUST-1 by adding Zn metal ion. From their research, a Zn-HKUST-1 material was obtained with a pore diameter in the range of 0.56 $\mathrm{nm}$ to $1.10 \mathrm{~nm}^{8}$. Next, Li-Yan and co-workers in 2012 synthesized HKUST-1 through a modulation method conditioned at room temperature by varying the additions of modulators such as benzoic acid, salicylic acid, propionic acid and acetic acid. It was found that HKUST-1 had a BET surface area in

Rasayan J. Chem., 12(3), 1653-1659(2019)

http://dx.doi.org/10.31788/RJC.2019.1231968

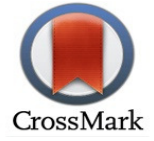


RASĀYAN J. Chem.

Vol. 12 | No. 3 |1653 - 1659| July - September | 2019

between 1171 to $1273 \mathrm{~m}^{2} / \mathrm{g}^{9}$, bigger than that of the synthesized HKUST-1 by Chui and co-workers ${ }^{10}$ and Chowdhury and co-workers ${ }^{11}$, which were $692 \mathrm{~m}^{2} / \mathrm{g}$ and $857 \mathrm{~m}^{2} / \mathrm{g}$, respectively. This shows that adding a modulator to the reaction system can increase the surface area of the obtained HKUST-1 material. Recently, Israr and co-workers ${ }^{12}$ have successfully synthesized HKUST-1 in a variety of solvents under the ultrasonic radiation condition. Based on the $\mathrm{N}_{2}$ adsorption-desorption isotherms, both types of research showed that the HKUST-1 obtained had a type I isotherm, characteristic to a microporous material ${ }^{9}$.

The microporosity characteristic limits the applications of the HKUST-1 material making it only usable for adsorption of small-sized particles. Hence, the porosity of the HKUST-1 material needs to be enlarged into a mesoporous, with pore diameters of around 2 to $50 \mathrm{~nm}$, making the reactant molecules easier to access the active sites of the HKUST- $1^{12}$. Various methods have reported for preparing mesoporous materials. In order to obtain metal-organic frameworks with hierarchical porosity, surfactants are used as molecular or soft templates ${ }^{13}$. The surfactant-thermal strategy was used as a method to obtain various porous materials ${ }^{14}$. In our previous works, mesoporous ZSM-5 was obtained adding hexadecyltrimethylammonium bromide $(\mathrm{CTAB})$ surfactant in the synthesis process. From the $\mathrm{N}_{2}$ adsorption-desorption measurement, the obtained solids showed a type IV isotherm which was a typical of a mesoporous material ${ }^{15}$.

In this study, the synthesis of MOF type HKUST-1 was carried out by a solvothermal method using a solvent mixture of ethanol, N,N dimethylformamide (DMF) and water at a temperature of $100{ }^{\circ} \mathrm{C}$ and also by adding a CTAB surfactant and an acid acetate modulator. Mesoporous HKUST-1 crystals with uniform surface morphology, high crystallinity, BET surface area, pore diameter and pore volume was obtained.

\section{Material and Methods}

\section{EXPERIMENTAL}

All chemicals of copper(II) nitrate trihydrate $\left[\mathrm{Cu}\left(\mathrm{NO}_{3}\right)_{2} \cdot 3 \mathrm{H}_{2} \mathrm{O}, 99 \%\right]$, benzene-1,3,5-tricarboxylic acid [( $\left.\left.\mathrm{H}_{3} \mathrm{BTC}\right), 98 \%\right]$, N,N-dimethylformamide (DMF, 99.8\%), ethanol (99.9\%), methanol (99.9\%), cetyltrimethylammonium bromide (CTAB, 97\%) and acetic acid (99.9\%) were supplied by Merck and used as received.

The method for HKUST-1 synthesis was the same as reported by Chowdhury with the modification of adding CTAB followed by adding acetic acid modulator ${ }^{11}$. At first, $0.67 \mathrm{~g}$ of $\mathrm{H}_{3} \mathrm{BTC}$ was dissolved in a $20 \mathrm{~mL}$ mixture of ethanol: $\mathrm{DMF}=1: 1$. In the other container, $1.39 \mathrm{~g}$ of $\mathrm{Cu}\left(\mathrm{NO}_{3}\right)_{2} \cdot 3 \mathrm{H}_{2} \mathrm{O}$ was dissolved in a $10 \mathrm{~mL}$ of demineralized water. Both solutions were then mixed together in a vial bottle with a lid, and at the same time, the CTAB was added, with molar ratios of CTAB to $\mathrm{H}_{3} \mathrm{BTC}$ as shown in Table 1 . The mixture was then stirred with a magnetic stirrer for $15 \mathrm{~min}$, followed by heating in an oven at $100{ }^{\circ} \mathrm{C}$ for $10 \mathrm{~h}$. After the heating process, the reaction mixture was cooled down at room temperature and put to idle for 2 days. The precipitates were submerged inside a $20 \mathrm{~mL}$ of DMF for 24 hours and then submerged in a $30 \mathrm{~mL}$ methanol at a temperature between $40{ }^{\circ} \mathrm{C}$ to $55{ }^{\circ} \mathrm{C}$ for 3 days. The obtained solid from the process of washing was dried at room temperature and weighed. The synthesis of HKUST-1 was repeated by adding different amounts of CTAB and acetic acid into the reaction system. The obtained materials were then denoted as $\mathrm{CuBTC}(\mathrm{Sx})$ and $\mathrm{CuBTC}(\mathrm{SxMy})$, where $\mathrm{x}$ and y were the ratio of surfactant and acetic acid concentration to ligands, respectively.

\section{Characterization Method}

The XRD patterns were recorded with a Philips powder diffractometer model X'Pert PN-1830 using a $\mathrm{Cu}-\mathrm{K} \alpha$ radiation source of wavelength $\lambda=1.5418 \AA$, in the $2 \theta$ range of $5-50^{\circ}$ with a step of $0.02^{\circ}$. The FTIR spectra were collected on a Shimadzu FTIR spectrophotometer using $\mathrm{KBr}$ disks at room temperature in the wavenumber range of $400-4000 \mathrm{~cm}^{-1}{ }^{16}$. The scanning electron microscopy (SEM) observations were performed on an EVO MA 10 "Carl Zeiss". BET surface area, as well as pore size of the samples, were determined from nitrogen adsorption-desorption isotherms at liquid nitrogen temperature of $-196{ }^{\circ} \mathrm{C}$ with a Quantachrome ${ }^{\circledR}$ ASHIQ winTM Gas Sorption Instruments. Prior to analysis, the samples were degassed at $150{ }^{\circ} \mathrm{C}$ for $8 \mathrm{~h}$ under vacuum. 
RASĀYAN J. Chem.

Vol. 12 | No. 3 |1653 - 1659| July - September | 2019

\section{RESULTS AND DISCUSSION}

From the synthesis process, the light blue powders were obtained, a resemblance to the HKUST-1 solids obtained from the previous research ${ }^{17}$. The mass of the obtained solids decreased with the increase in the amount of CTAB added. Furthermore, adding acetic acid modulator into the reaction systems also caused a further decrease in the mass of the solids. In this case, the modulator (acetic acid) competed with the linker molecules $\left(\mathrm{H}_{3} \mathrm{BTC}\right)$ for the coordination sites at the secondary building unit (SBU). Nucleation and growth then proceeded at a reduced rate due to some exchange between the coordinated modulator with the bridging linker molecules, which led to a decrease in reaction rates ${ }^{18}$.

The diffraction patterns of the whole obtained solids, including those synthesized with adding CTAB (Fig.-1), shows the characteristic peaks with high intensity at $2 \theta=11.5^{\circ}$, followed by other characteristic peaks at $2 \theta=6.7^{\circ}, 9.5^{\circ}$ and $13.4^{\circ}$. The results match the diffraction pattern of the HKUST- 1 materials, which had been reported by Liu and co-workers ${ }^{19}$. In addition, no peaks of $\mathrm{CuO}$ (at $2 \theta=35.5^{\circ}$ dan $38.7^{\circ}$ ) or $\mathrm{Cu}_{2} \mathrm{O}$ (at $\left.2 \theta=36.43^{\circ}\right)^{20}$ were found in the diffractogram of the synthesized solids. These results indicate that the addition of $\mathrm{CTAB}$ into the reaction system has no influence on the frame structure formation of the HKUST-1 material. Besides, the addition of CTAB and acetic acid into the reaction system have resulted in solids with the same diffractogram pattern as the HKUST-1 that had been reported (Fig.-2), even though the intensity of the characteristic peaks decreases.

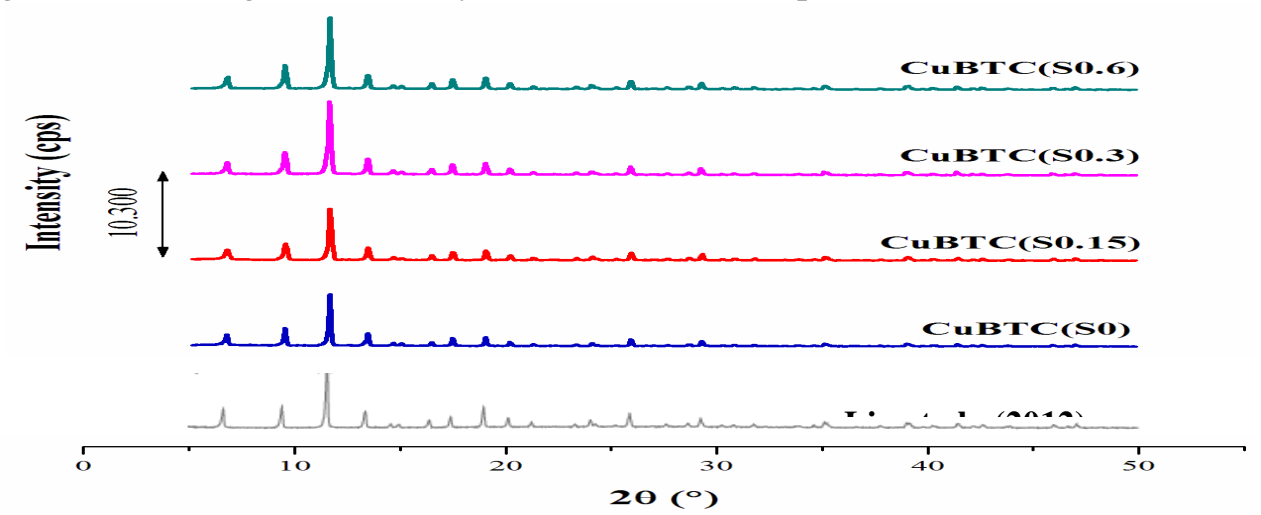

Fig.-1: XRD Patterns of Samples Obtained in Variation Amounts of CTAB Surfactant.

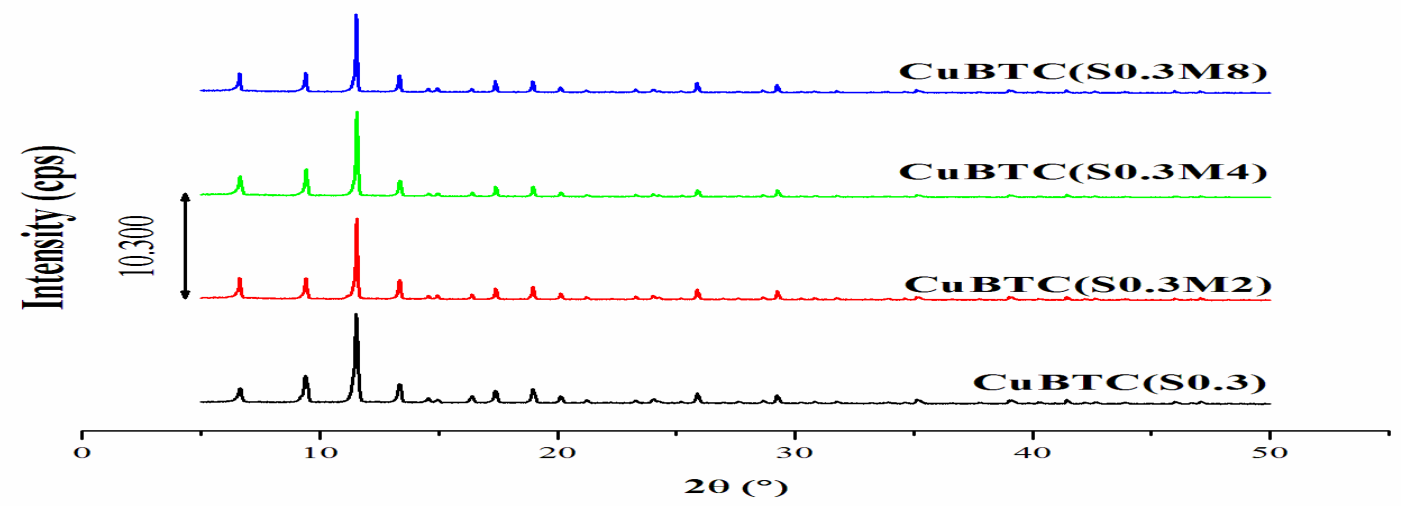

Fig.-2: XRD Patterns of Samples Obtained in Variation Amounts of Acetic Acid Modulator.

The FTIR spectra on all the synthesized solids as shown in Figure 3, have peak absorption characteristics on the same wavenumber as the reported HKUST $-1^{19}$. Figure- 3 also shows the infrared spectrum of the CTAB compound had a weak absorption band on the wavenumbers of $1468 \mathrm{~cm}^{-1}\left(-\mathrm{CH}_{2}\right.$ bending) and $1380 \mathrm{~cm}^{-1}\left(\mathrm{CH}_{3}-\mathrm{R}\right)$ and a strong absorption band on the wavenumbers of 2922 dan $2850 \mathrm{~cm}^{-1}\left(-\mathrm{CH}_{2}\right.$ stretching), which indicates the existence of a bond on the cluster of hydrophobic surfactants CTAB. The typical absorption bands of the CTAB compounds did not show on the infrared spectrum of all the synthesized HKUST-1 solids, which indicate that the CTAB surfactants have been removed perfectly during the process of methanol washing. The infrared spectrum of the $\mathrm{H}_{3} \mathrm{BTC}$ compound can also be seen in Fig.-3. 
RASĀYAN J. Chem.

Vol. 12 | No. 3 |1653 - 1659| July - September | 2019

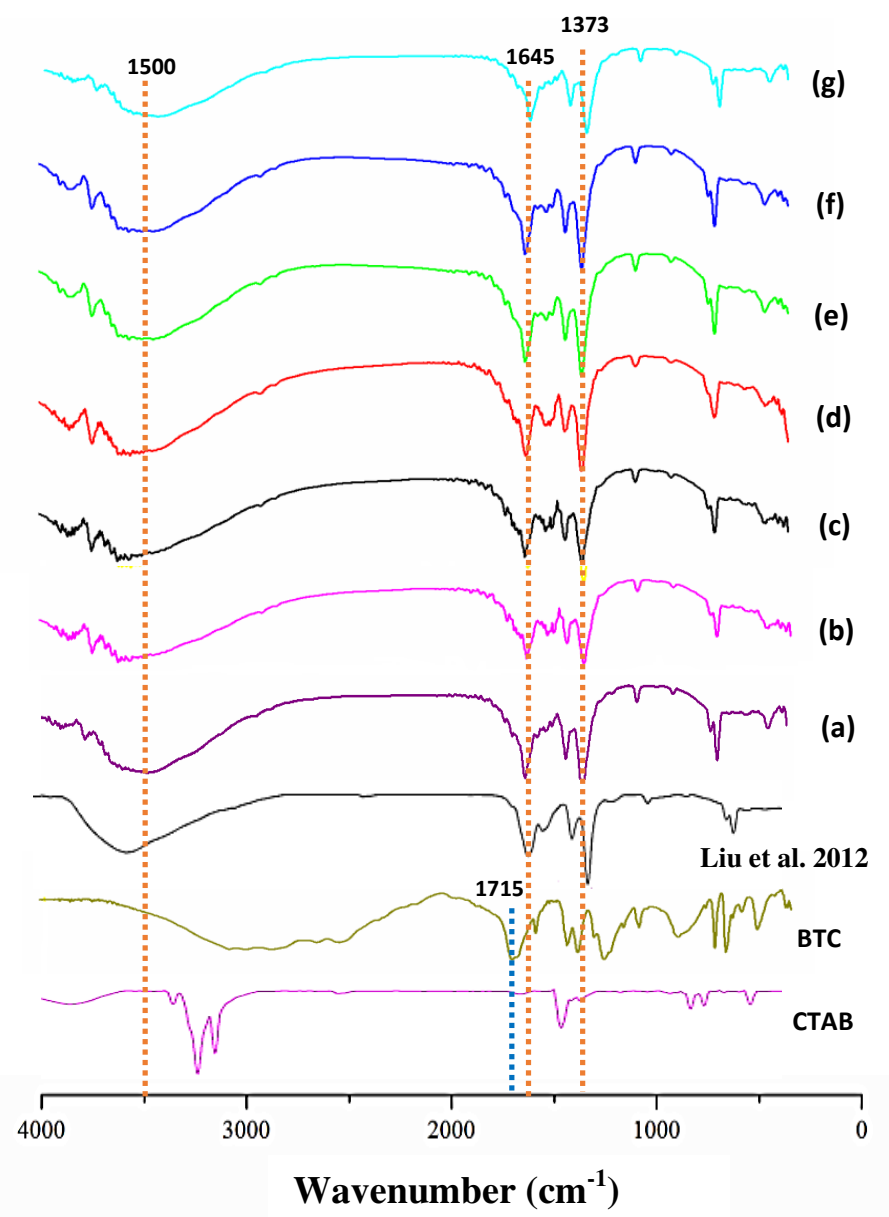

Fig.-3: FTIR Spectra of All the Obtained CuBTC(Sx) Solids (a) $\mathrm{x}=0$; (b) $\mathrm{x}=0,15$; (c) $\mathrm{x}=0,3$; (d) $\mathrm{x}=0,6$; CuBTC(S0,3My) (d) y=2; (e) $y=4$; (f) $y=8$.

The wide absorption band on the wavenumbers of 2400-3200 $\mathrm{cm}^{-1}$ shows an existence of the $\mathrm{OH}$ stretching from the carboxylate clusters on the $\mathrm{H}_{3} \mathrm{BTC}$ spectrum and experience a shifting, changing the wavenumbers into $3300-3500 \mathrm{~cm}^{-1}$ on the (a)-(g) spectrum. This shows that the existence of the $\mathrm{OH}$ clusters may come as an effect of the $\mathrm{H}_{2} \mathrm{O}$ that has been entered into the pores of HKUST-1. The emergence of the absorption band at the wavenumber of $1715 \mathrm{~cm}^{-1}$ on the $\mathrm{H}_{3} \mathrm{BTC}$ spectrum shows the existence of $\mathrm{C}=\mathrm{O}$ stretching bonds, in which after complexation with the $\mathrm{Cu}^{2+}$ ion, the peak has shifted into wavenumber of $1645 \mathrm{~cm}^{-1}$ on the (a)-(g) spectra. This fact indicates that the $\mathrm{H}_{3} \mathrm{BTC}$ ligands experienced a deprotonating caused by the DMF and ethanol solvent in the process of synthesis. The absorption band at the wavenumber of $1452 \mathrm{~cm}^{-1}$ showed the existence of aromatic $\mathrm{C}=\mathrm{C}$ bonds from the benzene structure on the organic ligands. The absorption band at the wavenumber of $1373 \mathrm{~cm}^{-1}$ shows existence of $\mathrm{C}-\mathrm{O}$ stretching bonds on the $\mathrm{C}-\mathrm{OH}$ carboxylate acid cluster. On the fingerprint area of the (a)-(g) spectra, there was an absorption band at the wavenumber of $\sim 700 \mathrm{~cm}^{-1}$, which came from a stretching vibration of the $\mathrm{Cu}-\mathrm{O}$ on the HKUST- $1^{11}$.

Morphologies of the various CuBTC samples were examined by SEM. As are shown in Fig.-4, SEM images reflect the crystallite evolutions of CuBTC. CuBTC(S0) sample shows an octahedral shape crystal morphology which is in accordance with the results for HKUST-1 reported by Wang and co-workers ${ }^{3}$.

The additions of CTAB in the synthesis process have slightly altered the surface morphologies of the obtained CuBTC. SEM image of the $\mathrm{CuBTC}(\mathrm{S} 0.3)$ is still dominated by crystals with octahedral shaped morphologies (Fig.-4b). However, on the CuBTC(S0.6) samples, many of the crystals are seen to be in the shape of imperfect and irregular octahedral (Fig.-4c). This indicates that on an excessive amount of addition of CTAB into a reaction system stimulates the crystal structures formed to be more random. 
RASĀYAN J. Chem.

Vol. 12 | No. 3 |1653 - 1659| July - September | 2019

Further, the additions of both CTAB and acetic acid into a reaction system have caused the surface morphologies of the obtained solids to be out of place, as are shown in Fig.-4d and 4e. The SEM images of $\mathrm{CuBTC}(\mathrm{S} 0.3 \mathrm{M} 4)$ and the $\mathrm{CuBTC}(\mathrm{S} 0.3 \mathrm{M} 8)$ show irregular crystal morphologies with random size. The addition of acetic acid in the synthesis of CuBTC will give competitive coordination between monocarboxylic acid (acetic acid) and tricarboxylic acid. The intergrown structure of CuBTC(S0) is due to the continuous secondary nucleation of the CuBTC nuclei. When the competitive acetic acid joins, some copper clusters tend to combine with the acetic acid or exchange between acetic acid and linker molecules at the coordination sites. Therefore, the formation of the CuBTC nuclei is disfavored and fewer nuclei grow to well-defined octahedrons ${ }^{21}$.

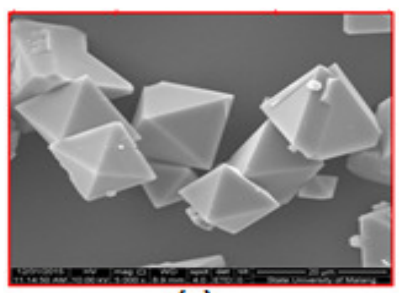

(a)

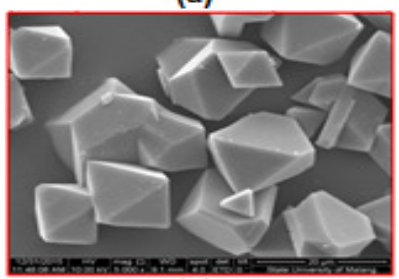

(c)

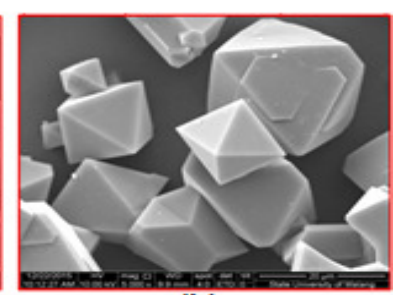

(b)

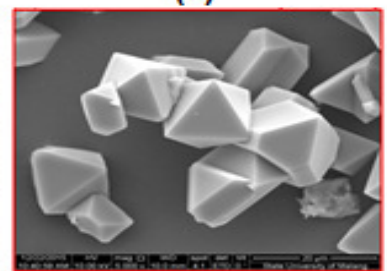

(d)

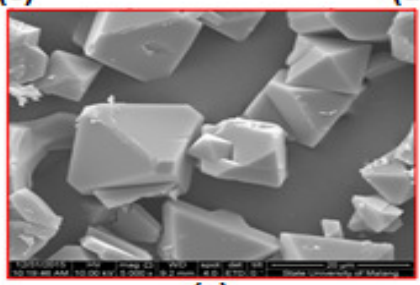

(e)

Fig.-4: SEM Images of (a) CuBTC(S0); (b) CuBTC(S0.3); (c) CuBTC(S0.6);

(d) $\operatorname{CuBTC}(\mathrm{S} 0.3 \mathrm{M} 4) ;(\mathrm{e}) \mathrm{CuBTC}(\mathrm{S} 0.3 \mathrm{M} 8)$

Nitrogen adsorption and desorption isotherms of $\mathrm{CuBTC}(\mathrm{S} 0), \mathrm{CuBTC}(\mathrm{S} 0.3)$ and $\mathrm{CuBTC}(\mathrm{S} 0.3 \mathrm{M} 4)$ are displayed in Fig.-5.

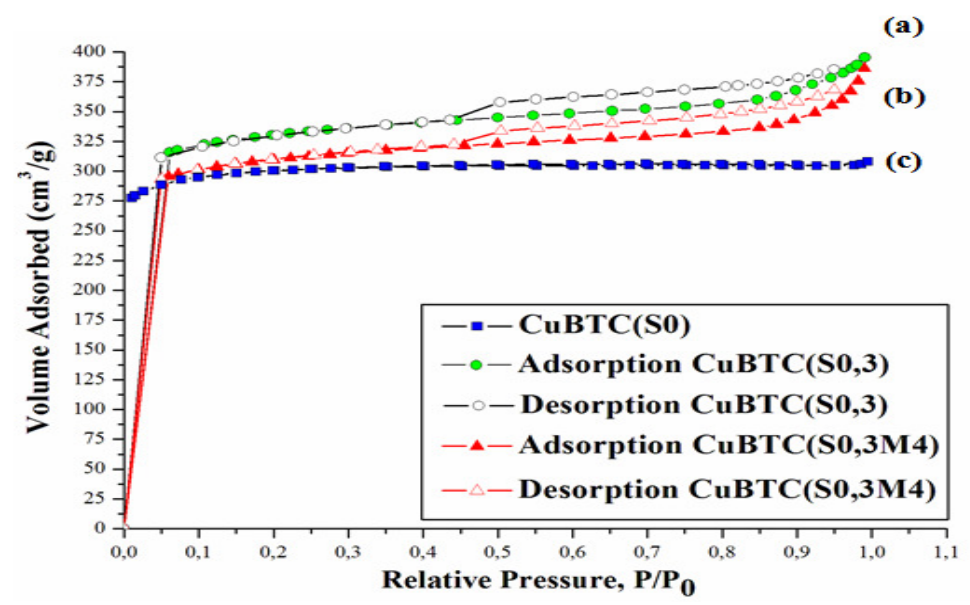

Fig.-5: $\mathrm{N}_{2}$ Adsorption and Desorption Isotherms of CuBTC(S0), CuBTC(S0.3) and CuBTC(S0.3M4).

The nitrogen adsorption at low pressure for all CuBTC samples is very high, indicating the presence of micropores. CuBTC(S0) has a BET surface area of $907 \mathrm{~m}^{2} / \mathrm{g}$, that is slightly higher than that of the previous reports ${ }^{10,11}$, as can be seen in Table-1. 
RASĀYAN J. Chem.

Vol. 12 | No. 3 |1653 - 1659| July - September | 2019

Table-1: BET Surface Areas, Pore Volumes and Pore Diameters of Samples

\begin{tabular}{c|c|c|c}
\hline Notation of Samples & BET Surface Area $\left(\mathrm{m}^{2} / \mathrm{g}\right)$ & Pore Diameter $(\mathrm{nm})$ & Pore Volume $\left(\mathrm{cm}^{3} / \mathrm{g}\right)$ \\
\hline CuBTC(S0) & 907 & 6.2 & 0.47 \\
\hline CuBTC(S0.3) & 1010 & 9.2 & 0.61 \\
\hline CuBTC(S0.3M4) & 946 & 7.5 & 0.59 \\
\hline \multirow{2}{*}{ HKUST-1 } & $857^{11}$ & - & $0.42^{11}$ \\
\cline { 2 - 4 } & $692^{10}$ & - & $0.33^{10}$ \\
\hline
\end{tabular}

Based on the IUPAC qualifications, $\mathrm{CuBTC}(\mathrm{S} 0)$ shows the type I isotherms with no hysteresis loops, indicating the absence of mesopores. On the contrary, $\mathrm{CuBTC}(\mathrm{S} 0.3)$ and $\mathrm{CuBTC}(\mathrm{S} 0.3 \mathrm{M} 4)$ show a typical type IV isotherms with an $\mathrm{H} 3$-type hysteresis loops at relative pressure $\mathrm{P} / \mathrm{P}_{0}$ between $0.45-0.94$, which demonstrates the formation of mesopores and the presence of slit-like pores ${ }^{22}$. In addition, the BET surface areas of CuBTC(S0.3) and CuBTC(S0.3M4) solids are $1010 \mathrm{~m}^{2} / \mathrm{g}$ and $946 \mathrm{~m}^{2} / \mathrm{g}$, respectively, higher than that of $\mathrm{CuBTC}(\mathrm{S} 0)$, which is consistent with XRD results. The results confirm the role of surfactant CTAB in the formation of mesopores ${ }^{23}$.

The pore size distribution of $\mathrm{CuBTC}(\mathrm{S} 0), \mathrm{CuBTC}(\mathrm{S} 0.3)$ and $\mathrm{CuBTC}(\mathrm{S} 0.3 \mathrm{M} 4)$ modeled by the BJH method are shown in Fig.-6.

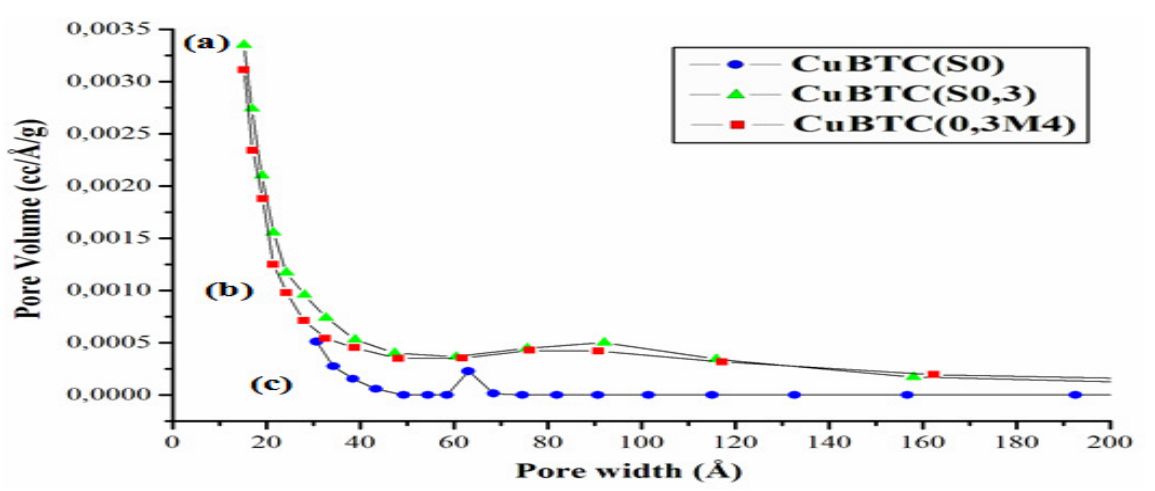

Fig.-6: BJH Pore Distributions of CuBTC(S0), CuBTC(S0.3) and CuBTC(S0.3M4).

As can be seen, the $\mathrm{CuBTC}(\mathrm{S} 0)$ solids have the lowest pore volume of $0.47 \mathrm{~cm}^{3} / \mathrm{g}$ with a pore diameter of $62 \AA(6.2 \mathrm{~nm})$, compared to the $\mathrm{CuBTC}(\mathrm{S} 0.3)$ with pore volume and pore diameter of $0.61 \mathrm{~cm}^{3} / \mathrm{g}$ and 9.2 $\mathrm{nm}$, respectively, as well as CuBTC(S0.3M4) with pore volume and pore diameter of $0.59 \mathrm{~cm}^{3} / \mathrm{g}$ and 7.5 $\mathrm{nm}$, respectively. This result also indicates the function of CTAB as a template in the process of forming the MOF mesopores ${ }^{23}$.

\section{CONCLUSION}

Mesoporous HKUST-1 with high crystallinity and BET surface area, as well as regular octahedron surface morphology have successfully been synthesized using the solvothermal method in the presence of CTAB surfactant and acetic acid modulator. The highest level of crystallinity is exhibited by the $\mathrm{CuBTC}(\mathrm{S} 0.3)$, that has been synthesized in the presence of CTAB with $\mathrm{H}_{3} \mathrm{BTC}$ to CTAB molar ratio of 0.55 to 0.3 . The $\mathrm{CuBTC}(\mathrm{S} 0.3)$ also shows a typical type IV isotherms of mesoporous materials with highest BET surface area, pore volume and pore diameter of $1010 \mathrm{~m}^{2} / \mathrm{g}, 0.61 \mathrm{~cm}^{3} / \mathrm{g}$ and $9.2 \mathrm{~nm}$, respectively However, on excessive amount of addition of CTAB and acetic acid modulator has resulted in a decrease in crystallinity, BET surface area, pore volume and pore diameter of the obtained solids.

\section{ACKNOWLEDGMENT}

We gratefully acknowledge funding from the Ministry of Research, Technology and Higher Education, Republic of Indonesia, through Postgraduate Research Grand for the year of 2017, and the Department of Chemistry, Institut Teknologi Sepuluh Nopember, Surabaya.

\section{REFERENCES}

1. R.J. Kuppler, D.J. Timmons, Q.R. Fang, J.R. Li, T.A. Makal, M.D. Young, D. Yuan, D. Zhao, W. Zhuang, and H.C. Zhou, Coord. Chem. Rev., 253(23-24), 3042(2009), DOI: 
RASĀYAN J. Chem.

Vol. 12 | No. 3 |1653 - 1659| July - September | 2019

10.1016/j.ccr.2009.05.019

2. Y. Pan, D. Heryadi, F. Zhou, L. Zhao, G. Lestari, H. Su, and Z. Lai, Cryst. Eng. Comm., 13(23), 6937 (2011), DOI: $10.1039 / \mathrm{C} 1 \mathrm{CE} 05780 \mathrm{D}$.

3. F. Wang, H. Guo, Y. Chai, Y. Li, and C. Liu, Microporous Mesoporous Mater., 173, 181 (2013), DOI: $10.1016 /$ j.micromeso.2013.02.023

4. S. Cao, G. Gody, W. Zhao, S. Perrier, X. Peng, C. Ducati, D. Zhao, and A.K. Cheetham, Chem. Sci., 4(9), 3573 (2013), DOI:10.1039/C3SC51336J.

5. K.-S. Lin, A.K. Adhikari, C.-N. Ku, C.-L. Chiang, and H. Kuo, Int. J. Hydrogen Energy, 37(18), 13865 (2012), DOI: 10.1016/j.ijhydene.2012.04.105

6. L. Alaerts, E. Séguin, H. Poelman, F. Thibault $\square$ Starzyk, P.A. Jacobs, and D.E. De Vos, Chem. Eur. J., 12(28), 7353 (2006), DOI:10.1002/chem.200600220

7. Y.-K. Seo, G. Hundal, I.T. Jang, Y.K. Hwang, C.-H. Jun, and J.-S. Chang, Microporous Mesoporous Mater., 119(1-3), 331 (2009), DOI: 10.1016/j.micromeso.2008.10.035

8. J.I. Feldblyum, M. Liu, D.W. Gidley, and A.J. Matzger, J. Am. Chem. Soc., 133(45), 18257 (2011), DOI: $10.1021 / \mathrm{ja} 2055935$

9. L.-Y. Na, R.-N. Hua, G.-L. Ning, and X.-X. Ou, Chem. Res. Chinese Univ., 28(4), 555 (2012).

10. S.S.Y. Chui, S.M.F. Lo, J.P.H. Charmant, a G. Orpen, and I.D. Williams, Science, 283, 1148 (1999), DOI:10.1126/science.283.5405.1148.

11. P. Chowdhury, C. Bikkina, D. Meister, F. Dreisbach, and S. Gumma, Microporous Mesoporous Mater., 117(1-2), 406 (2009), DOI:10.1016/j.micromeso.2008.07.029

12. D. Bradshaw, S. El-Hankari, and L. Lupica-Spagnolo, Chem. Soc. Rev., 43(16), 5431 (2014), DOI: 10.1039/C4CS00127C.

13. H.-S. Lu, L. Bai, W.-W. Xiong, P. Li, J. Ding, G. Zhang, T. Wu, Y. Zhao, J.-M. Lee, and Y. Yang, Inorg. Chem., 53(16), 8529 (2014), DOI:10.1021/ic5011133

14. R. Thahir, A.W. Wahab, N.L. Nafie, and I. Raya, Rasayan J. Chem., 12(3), 1117(2019), DOI: 10.31788/RJC.2019.1235306.

15. R. Ediati, A. Mukminin, and N. Widiastuti, Indones. J. Chem., 17(1), 30(2017), DOI: $10.22146 /$ ijc. 23563

16. H. Kusumastuti, W. Trisunaryanti, I.I. Falah, and M.F. Marsuki, Rasayan J. Chem., 11(2), 522 (2018), DOI:10.31788/RJC.2018.1122061

17. R.S. Kumar, S.S. Kumar, and M.A. Kulandainathan, Microporous Mesoporous Mater., 168, 57-64 (2013), DOI: 10.1016/j.micromeso.2012.09.028

18. D. Zacher, A. Baunemann, S. Hermes, and R.A. Fischer, J. Mater. Chem., 17(27), 2785 (2007), DOI: 10.1039/B703098C.

19. Q. Liu, L.-N. Jin, and W.-Y. Sun, Chem. Commun., 48(70), 8814(2012), DOI: 10.1039/C2CC34192A.

20. M. Hartmann, S. Kunz, D. Himsl, O. Tangermann, S. Ernst, and A. Wagener, Langmuir, 24(16), 8634 (2008), DOI:10.1021/la8008656

21. A. Umemura, S. Diring, S. Furukawa, H. Uehara, T. Tsuruoka, and S. Kitagawa, J. Am. Chem. Soc., 133(39), 15506 (2011), DOI: 10.1021/ja204233q

22. F.W. Artanti, W. Trisunaryanti, M. Pongsendana, Triyono, I.I. Falah, and M.F. Marsuki, Rasayan J. Chem., 11(4), 1433(2018), DOI: 10.31788/RJC.2018.1143073.

23. J. Zhuang, D. Ceglarek, S. Pethuraj, and A. Terfort, Adv. Funct. Mater., 21(8), 1442 (2011), DOI: 10.1002/adfm.201002529

[RJC-1968/20017] 